\title{
Telehealth and telemedicine: how the digital era is changing standard health care
}

This article was published in the following Dove Press journal:

Smart Homecare Technology and TeleHealth

20 June 2017

Number of times this article has been viewed

\author{
Yasser El-Miedany \\ King's College, London, UK
}

Correspondence: Yasser El-Miedany Rheumatology Department, Darent Valley Hospital, Darenth Wood Road, Dartford, Kent DA2 8DA, UK

Email drelmiedany@rheumatology4u.com

\begin{abstract}
The revolution in digital technology has transformed our lives, and electronic advances are expected to expand. At the same time, personal attitudes toward technology developments and digital health care are also changing positively. Younger generations and older adults have started to enjoy the outcomes of the recent technology progresses. Soon, smart gadgets are expected to play an important role in health care and day-to-day management of the patients, and hence will be able to renovate medical services and facilitate real improvement in the patients' self-management. The challenge is how to make most of these technical advances patient friendly, and explore ways to avoid the risks, particularly in regard to privacy. This article discusses the growing role of telehealth in standard health care, the facility and impact of using digital technology in day-to-day patients' management and the best evidence available from those using digital technology on the front line. Keywords: telemedicine, telehealth, e-PROMs, e-comorbidity, rheumote, electronic medical record, e-health
\end{abstract}

\section{Introduction}

The last decade has seen a significant development in information technology. This was paralleled by a concurrent wave of advance in science-based medical knowledge. Marrying the two innovations gave birth to telehealth (also referred to as telemedicine or ehealth). Telehealth is defined as "the exchange of information at a distance, embraces a variety of practical applications including transmitting images such as radiographs, advising patients over the telephone using computer-based protocols, or more comprehensive activities, such as remote surgical procedures and consultations". ${ }^{1}$

Medicine is a data-rich enterprise. Changing the health care infrastructure through replacing the traditional paper-based patient's medical record by an up-to-date electronic health record (eHR) can transform the way health care is operated. With digital health care, the patient's medical information will be accessible wherever and whenever it is required, consequently, this will reflect positively on the treating physician's ability to make well-informed management decisions safely and comprehensively.

There are several benefits in adopting eHRs service, which greatly outweigh the cost of implementation. Its value was not only confined to the patients or health care professionals but also extended to include the patient-physician relationship and setting up treatment protocols tailored to the patient's needs. It has also helped in following the patients' medical status, disease activity, functional abilities, quality of life, medication monitoring and comorbidity(ies). ${ }^{2}$ This paved the way to a new trend in medicine which relies on computers and digital gadgets. This article will discuss the use of modern technology in the standard clinical practice, its direct impact on health

Smart Homecare Technology and TeleHealth 20I7:4 43-5I

\section{3}

(c) (i) (5) 2017 El-Miedany. This work is published and licensed by Dove Medical Press Limited. The full terms of this license are available at https://www.dovepress.com/terms. BY NC php and incorporate the Creative Commons Attribution - Non Commercial (unported, v3.0) License (http://(creativecommons.org/licenses/by-nc/3.0/). By accessing the work you hereby accept the Terms. Non-commercial uses of the work are permitted without any further permission from Dove Medical Press Limited, provided the work is properly attributed. For permission for commercial use of this work, please see paragraphs 4.2 and 5 of our Terms (https://www.dovepress.com/terms.php). 
care delivery, setting up services tailored to the patient and real-time monitoring of the disease vital signs and comorbidity. It will not focus on how technology will be like in the future, but rather, what will health care professionals be like.

\section{Electronic health care}

New terms have been introduced to the modern medicine literature, including electronic medical, health and personal records. Although these terms have been commonly used over the past years, there are still concerns as their meanings and differences among them remain unclear and confusing to the reader. An electronic medical record (eMR) includes the standard medical and clinical data gathered in one provider's office. Therefore, an eMR represents the digital version of a paper chart that contains the entire patient's medical history from one practice. ${ }^{3}$ An eMR is mostly used by providers for diagnosis and treatment. However, the information stored in eMRs cannot be shared with other providers outside the practice. A patient's medical information might even have to be printed out and delivered by mail to specialists and other members of the care team. In contrast, eHRs go beyond the data collected in the provider's office and include a more comprehensive patient information. Therefore, eHRs are designed to contain and share the patients' data from all providers involved in their care. eHR data can be created, managed and consulted by authorized providers and staff from more than one health care organization. Unlike eMRs, eHRs also permit the patients' health record to move with them - to other health care providers, specialists, hospitals, nursing homes and even across geographical regions. ${ }^{4}$

Electronic personal health record (ePHR) represents one step further. It is an online document with information about the person's health (including also the health of family members) that the person has to keep up-to-date for easy reference. Using the person's ePHR enables tracking of his/her family's health information, such as the date of the children's immunizations, last physical examination, allergies or a list of family medicines, allergies, major illnesses and operations. Many ePHRs are easy to use and may be provided free from health care providers, the government or private companies (who tend to charge a monthly or annual fee for this service). More recently, apps have been developed to do the same role. The availability of the ePHR on the web enabled the person to get into and manage his/her health information from anywhere. Empowering the people to collect, view, manage and share their health information electronically will in turn give the person the opportunity to take a more active role in managing his/her health care. ${ }^{5}$ Figure 1 depicts the meaning and main characteristics of the three terms.

\section{Effect and effectiveness}

Although many physicians have welcomed the potential of telehealth, the uptake has not been that positive as there were concerns about their limitations and the problems that may arise on implementing them in routine patients' care. ${ }^{6}$ Radiology has led the way, where radiologic images are transmitted for reporting. Excluding interventional radiology, radiologists rarely have face-to-face contact with the patients. Teleradiology has the advantages of being, inherently, a technologybased specialty and the fact that it is possible to gather large numbers of stored images, hence it is feasible to evaluate their diagnostic accuracy. ${ }^{1}$ Dermatology has also explored the transfer of photographic images of skin lesions, as has

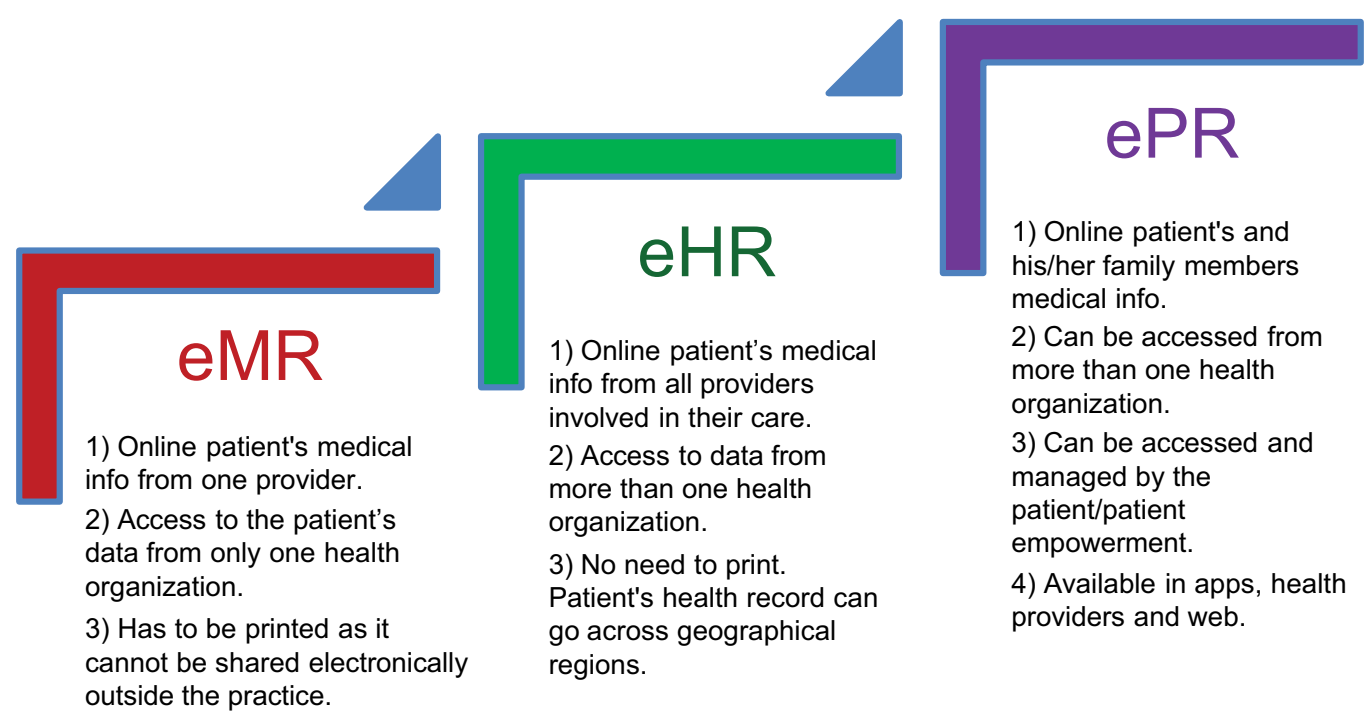

Figure I Electronic health care: characteristics and differences among the three main telehealth items.

Abbreviations: eHR, electronic health record; eMR, electronic medical record; ePR, electronic personal record; info, information. 
pathology with histopathology slides. ${ }^{7}$ Later, it becomes relatively common to send electrocardiograms electronically for interpretation elsewhere, and physicians are becoming increasingly familiar with telecardiology services. ${ }^{8}$

With the familiarity with telehealth care and the worldwide stretched medical services, the scope of telemedicine expanded aiming at the reduction of the pressure on secondary or tertiary health care services and to provide clinical care at a distance. There are now several applications for telemedicine, such as telecare, distant interpretation of digitally stored images, referral services, teleconsultations, remote monitoring of patients living with chronic conditions, online continuing medical education and online provision of medical and health information to patients. It is especially beneficial for those in rural areas because it reduces the need to travel for medical care along with the related costs. ${ }^{9}$ Table 1 shows a summary of digital models of electronic health care services.

Current research shows the evidence of the effectiveness and acceptability of telemedicine. Davis et a ${ }^{10}$ showed that teleconsultations in rheumatology were both feasible and acceptable. They found that patients were satisfied with this method, and $84 \%$ felt that the care received was as good as an "in person" visit. Their study did depend on a skilled family physician in the targeted remote area, who performed a supervised joint examination as well as the requisite history, examination and presentation of relevant investigations. On the financial side, in addition to the fact that telehealth can generate revenue through attracting new patients into the system, telemedicine can deliver cost savings by improving the efficiency of health care. Rosenfeld et $\mathrm{al}^{11}$ instituted 24-hour remote management by trained offsite intensivists and compared the outcomes of patients admitted to an intensive care unit, in a hospital without intensivists staff, to standard services. Results revealed decreased patient mortality, shorter length of stay in the intensive care and lower costs incurred for the period that intensivist expertise was available through telehealth technologies.

\section{Telehealth in standard practice Teleclinics}

\section{Remote clinics}

Because of the interest in finding new ways to provide specialty medical services to people living in remote, usually rural communities, governments have taken the lead in setting up telemedicine clinics around the world. ${ }^{12}$ The lack of specialty expertise was another drive toward out of the box thinking toward linking health care centers in the more developed countries. Setting us such teleclinics had clear benefits for the patients, as well as a substantial educational yield for the referring physician. On another front, health maintenance organizations can provide service to potentially new referrals in relatively under-serviced areas..$^{13,14}$

\section{Digital clinics}

Email consultations emerged as a way to provide rapid access, regarding nonurgent cases. This was shown to improve communication with the professionals, save patients time as well as hospital resource and increase overall satisfaction. ${ }^{13}$ Video clinics have also been reported to be well received by the patients who tried them, particularly those who do not have easy personal access to their treating health care team. ${ }^{15}$

\section{Online triage}

Patient-led self-triage (which relies mainly on symptom checker and service directories) or health care professionalled online triage (using emails or web consults) has the potential to reduce demand particularly in stretched services, although the evidence is so far not strong. ${ }^{16,17}$ Therefore, more research is needed on how to engage patients with such interactive systems and its applicability in real-life practice.

\section{Online appointment booking}

Outpatient clinic appointment bookings and ordering repeat prescriptions online can improve patient outcome, pharmaceutical risk and enhance the patients' experience. Online booking not only will help to save resources and minimize

Table I Digitalization of the health care service

\begin{tabular}{|c|c|c|}
\hline Doctor & Patient & Hospital \\
\hline E-consultations/eclinics & Online triage & Online medical record \\
\hline Email clinics & Online appointment booking & Online services, eg, lad, radiology \\
\hline Video conference & Online patient education & Digital appointment booking system \\
\hline Web chat & Online self-management & Elibrary \\
\hline Remote clinics & Social media & Online source of information \\
\hline Telephone consultations & Online patient network & Online mandatory training \\
\hline Online prescription & Health apps & Interactive system check/message \\
\hline Telemonitoring & Online medical record access & Wearables \\
\hline Apps for health care professionals & E-shared decision making & Electronic discharge \\
\hline
\end{tabular}


the "did not attend" pattern but will also result in administrative efficiencies. Appointment confirmation is sent now by text messages rather than the traditional letter. Patients check in automatically on arrival, and called to be directed to the consultation rooms, laboratory or radiology suites. ${ }^{18}$

\section{The digital doctor}

"Will computers, simply, replace the treating doctor in the modern medical service?" "My doctors did not look at me at all during the consultation. He kept talking to me while his eyes were focusing on the computer looking at my referral letter, results of my blood tests and X-ray reports". These are examples of questions raised recently regarding how technology can alter the direct doctor-patient relationship and whether modern technology has been useful or destructive to the standard medical practice.

The recent expansion of knowledge base and biomedical evidence has led to information overload, which highlighted the need for a smart access to quality information resources. This, in turn, will enable the treating health care professional make informed decisions and ensure high-quality professional medical care is provided for the patients. The increasing prevalence of smart gadgets has paved the way for the treating health care professionals to take advantage of such rapidly growing flexible access to medical information. "Apps for health care professionals" are currently available on Apple Store and Google play. At some stage, the NHS UK started to offer an apps library, which has been reviewed by medical experts to ensure their clinical and medical safety; however, this has been closed in 2015 amid questions about App security. ${ }^{19}$

\section{The "e-doctor" era}

What is the impact then on the day-to-day medical practice? It has become now relatively common that health care professionals google uncommon/rare presentations or search for further medical information before seeing their patients faceto-face in the consulting room. Recent mobile applications can tap into networks of sensors, giving the treating doctors an ongoing updated access to their patients' monitors to be viewed on their smart gadgets from any location. In 2013, the creation of a proof-of-concept demonstration that uses a Google Glass ${ }^{\mathrm{TM}}$ head-mounted display was announced by Royal Philips and Accenture. The new gadget was developed for exploring innovative approaches to expand the efficiency and effectiveness of performing surgical procedures. ${ }^{20}$ In a demo, Google Glass was connected to Philips IntelliVue Solutions. The target was to assess the feasibility of patient vital signs smooth transfer into Google Glass, which has the potential of providing physicians with hands-free access to critical patients' clinical information. This innovative technique demonstrated how a doctor wearing the display could simultaneously remotely monitor a patient's vital signs and react to postsurgical procedure developments. A patient's vital signs could also be remotely monitored by a physician or enlist support from health care professionals in other locations.

Hospital services has also started to change its standard tactics to provide a modern digital service. In addition to the eMRs and one electronic file per patient, the patients now receive reminding messages on their smart phones regarding their hospital or investigation appointments, ${ }^{21}$ ordering of investigations such as laboratory tests or radiologic scans got paperless; electronic admission and discharge notes are the standard whereas e-prescription became essential to ensure speed of drug delivery and getting the primary care physician aware of any changes in the drug record. In concordance, hospital libraries started to offer electronic books and journals as the loans of printed material are declining. Hospital libraries also launched new services facilitating quick access to evidence-based medical research from mobile devices. Several apps such as Up-to-Date, DynaMed, Clinical Key and Best Practice, which provide access to an updated evidence-based medical information, have been made available to hospital doctors. However, the new trend of tapping into medical research while on the go may take some time to get more popular among doctors. ${ }^{22}$

\section{Digital patients}

The new patient-clinician relationship

Digitally enabled health care to create a new era of health service powered by patients, mobile technologies and online social networks has led to the development of a new digital generation of patients. Over the past years, statistical analysis revealed that patient-facing health care digital technology is growing rapidly reflecting the expanding interest the people has shown in using digital gadgets to manage their health and their lives in general. In real-life scenarios, this has reflected on the patient-clinician relationship where a new relationship style has emerged. Studies revealed that before going to the consulting room, a growing number of patients have already carried out an Internet search for a possible diagnosis or management for their symptoms. ${ }^{23}$ Furthermore, it became a usual scene that the patient's partner take their smart gadgets with them during the consultation to google the information given by the health care professional, while 
sitting in the consultation room. After the consultation, the patients may join a web site forum where they share views with other people living with similar symptoms or medical problem. On another front, "Dr. Google" is a new online service, in which Google reportedly has set up a new webbased facility on its search engine, which will allow users to get connected directly to a doctor via a video call. This call's aim is to discuss the google online search results when the users search for their symptoms or conditions, a possible diagnosis or some advice on how to properly deal with the patient's symptoms. Similar online services have been set up by different specialty doctors on "Facebook". Other doctors started having online video consultations using Skype or have educational channels on "Youtube". ${ }^{24}$ However, in spite of the limitations and apprehensions on online medical services, such as "Dr. Google's" and "Facebook", particularly regarding the newly introduced term "cyberchondria", the Internet remains to be a top health information destination for people trying to find an online answer for their queries. In 2013, a national survey carried out by Pew Research Internet project ${ }^{25}$ was published. It revealed that one in three American adults has carried out an online search to inquire about a health or medical condition. In another research carried out by Berland et $\mathrm{al}^{26}$ to evaluate online health information available in Internet search engines and web sites, the authors reported that online search engines for health check or information were not efficient. The authors found that coverage of key health information about web sites was poor and inconsistent, although the accuracy of the information provided is generally good and that high reading levels were required to comprehend web-based health information.

\section{Online access to records}

Although having online access to the patients' records is considered one of the most effective approaches to engage patients, highly valued by the patients for its potential to improve patient-doctor communication, adherence to lifestyle advice and shared decision making, evidence about the impact on demand is generally inconclusive. Studies revealed that it also has the potential to increase GP visits, telephone encounters, accident and emergency (A\&E) visits and hospitalizations. ${ }^{27}$ However, so far, no robust evidence is available regarding its impact on health outcomes. Furthermore, several governance concerns were raised around granting record access to vulnerable patients and the potential for others to exploit their data. Also, concerns were raised about the extent to which the third-party information is shared, if full record access is granted. Some strategies to mitigate against these risks have been suggested, including restricting access or redacting records wherever applicable. ${ }^{28}$ But this requires considerable resource and may mandate setting up a new business model.

\section{Digital led - tailored care service}

The main aim of implementing online sources of health information is to set up targeted interventions and peer support tailored to the patient's needs. Online information can help the treating health care professionals identify the areas of medical care, which require further support or management, hence set up a treatment program tailored to their need. In the meantime, it helps the patients handle their condition and have more achievable and productive outcomes with their relative health care team. Joining a patient network often help the patients to feel better, socially supported and have improved behavioral and clinical outcomes. There are also positive outcomes from targeted web-based interventions, particularly for arthritis, mental and sexual health. ${ }^{29-31}$

\section{Digital health apps}

In the last few years, there have been significant developments in the digital technology, which, in turn, led to an expansion in variable types of health applications and well-being wearable devices, giving the opportunity to closely monitor the person's behavior and gain insight into health changes over time. Wearable devices differ in how they handle this self-recorded health data. Although some devices simply present the data back to the user for further analysis, other tools can interpret the data in order to make it more meaningful to the person and perhaps stimulate a positive behavior change. ${ }^{23}$ Interestingly, health data can also be beneficial to more than just the user, and large scale health data analysis can support epidemiologic studies with positive impact on overall health and fitness. ${ }^{32}$

On another front, health apps have recently been developed to facilitate the use of smart gadgets to keep record of a wider range of parameters. While there is a wide variety of apps available in the market for basic health measures which simply act like active trackers, there are also several apps to help patients manage their medical condition/disease. There is growing evidence purporting that apps can have a positive impact on diet monitoring, physical activity, adherence to medication and chronic condition management, particularly for multiple sclerosis, Parkinson's disease, inflammatory arthritis and cardiovascular disease. The facility of enabling data synchronization provides better accessibility for analysis. The synchronized data can usually be accessed via a web interface in a prepared and visualized form. ${ }^{33}$ 
Apps that use established behavior change techniques, such as prompting goal setting, review and feedback on performance to encourage engagement, may prove increasingly valuable in helping to sustain behavior change.

\section{Digital research}

Digital technology has taken another step forward toward empowering doctors and medical researchers. The aim is to widen the scope and marry medical research to personal care. This was facilitated by the introduction of new research apps which helped to take medical research out of the laboratory to real-life experience. This did help to solve one of the major challenges facing medical researchers, which is recruiting participants. Apple has taken the lead in this field by developing CareKit and ResearchKit. ${ }^{34}$ People using iPhones all over the globe, who live with conditions such as parkinsonism, asthma, seizures, diabetes mellitus or COPD, have been invited to install an app that is specific for their condition. Other apps have also been developed for those living with hepatitis $\mathrm{C}$, melanoma and postpartum depression of even who sustained recent head injury (concussion). By signing up to the ResearchKit, researchers no longer need to travel to their hospitals or facility to fill out questionnaires or complete tasks; instead, using the advanced sensors in iPhone, activities can be performed to generate precise source of information and provide an objective meaningful outcome.

\section{Digital visual feedback: making data meaningful}

To support changing subject's behaviors over a period of time, data provided need to be meaningful to him/her. Earlier studies $^{35,36}$ revealed that showing lots of numbers and raw data to the user may be, in fact, discouraging. In the studies where patients were equipped with pedometers, results revealed that they lost their interest in the data collected after a period of time. To manage this challenge, wearable apps adopted new techniques to handle the data presentation issue aiming at preventing cognitive overload from processing lots of information. Ambient feedback has been reported easier for the user to process, with higher chance of increasing the user perception. ${ }^{37}$ Studies have shown that by using ambient displays, rather than exhibiting numerical values, it uses less cognitive resources and does not require much of the user's conscious attention, hence it was found to be more persuasive on human behavior. ${ }^{38}$ Ubit is a mobile application that includes an ambient, friendly display, which shows a nonliteral representation of the physical activity that the user has done. ${ }^{39}$ The display contains a garden image, and the user gains more flowers as they exercise more. An alternative approach is "Gamification and social incentives," which can serve also as a motivational tool. Gamification is the application of gaming elements within nongame contexts, which includes leader boards, point scoring and rewards. Pokemon Go is a game developed to reduce sedentary lifestyles by rewarding the users for catching more Pokemon creatures as the players keep on walking, hunting for them.

\section{Challenges}

Due to an increased availability of the smart gadgets and devices, wearable as well as mobile, apps have shown clear benefits to humans' health. ${ }^{26}$ However, more work is still needed to make them more adaptable to variable settings (subject to the gadget used or the condition the patient might have) and better social integration (whether through communication with other patients or health care professionals). Advanced apps should provide both the patient and the doctor a window into the patient's daily symptoms, give access to advice line and provide a facility for better insight and more personalized ongoing care. Another serious challenge is that most of the already available free apps provide third-party access and platforms to collect these personal health data. ${ }^{39}$ Unfortunately, so far, there have not been any standardized regulations, and no approval process or "Good App Seal of Approval" exists, although developers can seek approval for applications voluntarily. ${ }^{40}$ More work is expected from organization bodies to consider a universal protocol, which will protect the users' privacy and ensure a proper path for the data collected. The patients should be able to control what information they provide to which apps and have access to the data they have shared.

\section{Electronic patient-reported outcomes (ePROs)}

Since the patient-reported outcomes (PROs) were first used as an outcome measure in research studies in 1980s, it was soon realized that PRO data collection can play an important role in health care. ${ }^{41}$ Over the past few years, there has been a convergence in the development of patient-reported outcome measures (PROMs). Further developments were carried out toward integrating electronic PROMs (ePROMs) in an eHR and electronic disease activity monitoring formats. The target is to implement patient-centered management approach into standard clinical practice. ${ }^{42}$ Historically, eHRs began as an electronic version of the patient hospital record and clinics, which evolved later to include collective PROMs gathered over several patient's visits to the outpatient clinics. ${ }^{43}$ One 
advantage of this ePROMs service is that information collected can potentially be used for multiple different tasks, including outcome of medical management, quality assessment and improvement of clinical care, longitudinal research, audits as well as public reporting. ${ }^{44}$

Pilot studies were carried out to assess the possibility of integrating PROs into standard clinical practice. The use of ePROMs in standard practice for rheumatoid arthritis (RA) patients was assessed in recent study. ${ }^{2}$ Results revealed that nearly all the smart gadgets, including tablets, computers and smart phones, could be used to administer the outcome measure. Calculating the patient's disease activity parameters was feasible and in view of the disease activity scores calculated, relevant clinical actions tailored to the patient's condition were taken. Another recent study ${ }^{45}$ was carried out in patients with systemic lupus erythematosus (SLE) to assess the applicability of using ePROMs in the routine care and monitoring of SLE disease activity/flares over a 24-month period. The outcomes of the ePROMs were also studied for its association with adherence to medical management and organ damage adjusted for potential confounding factors. Results revealed that ePROMs might have a potential diseasemodifying effect as it facilitated close monitoring of disease activity with an option of management escalation whenever indicated. Disease activity as measured by Systemic Lupus Erythematosus Disease Activity Index (SLEDAI) over a 24-month observation period predicted the risk of subsequent organ damage independently of other known risk factors. Similar findings were reported in patients living with cancer. ${ }^{46}$ Results revealed that such smart electronic systems have the ability to support several clinical activities, including assessment of symptoms, disease activity, untoward side effects or toxicity related to chemotherapy/radiotherapy, postoperative observation and management of symptom over the palliative care period.

\section{E-comorbidity}

Shortened life expectancy in patients with chronic conditions has been linked to the associated comorbidities. This highlighted the importance of screening and management of associated comorbidity(ies) as a requirement for proper patient management. Understanding the comorbidity burden and its impact facilitated the identification of its role in the patient's prognosis and premature mortality risk. The integration of electronic comorbidity assessment in routine clinical care has attracted attention over the past few years. While the outcomes of earlier research studies seem very positive, further work is expected over the coming years.
A study published in the American College of Rheumatology conference $(2016)^{47,48}$ was carried out to study the validity of an electronically recorded and monitored comorbidity in day-to-day rheumatology clinical care. The target was assessing the possibility of setting up a digital service provided to rheumatoid and psoriatic arthritis patients to identify the presence of any associated comorbid conditions and weigh the e-comorbidity assessment impact on the patients' medical care and adherence to therapy. A cohort of 448 RA and 437 psoriatic arthritis subjects was included in the study. Adopting RA comorbidity index ${ }^{49}$ and psoriatic arthritis comorbidity index, ${ }^{50}$ electronic patient-reported comorbidity questionnaire was developed. This was included as a part of ePROMs tool used to monitor the patient's disease activity. The calculated comorbidity risk and sensitivity, specificity, positive and negative predictive values of the developed electronic comorbidity tool were compared with The 10th revision of the International Classification of Diseases (ICD10) medical record (standard reference) and rheumatology clinic visit outcomes. A cohort of 241 RA patients and 252 psoriatic arthritis patients who continued their clinical care per standard protocols was also monitored for 2 years as a control group. Primary end point was no inferiority of the electronic versus standard comorbidity assessment outcomes in standard rheumatology practice. Secondary end point was the patients' adherence to their medications and actions taken to monitor/manage the comorbidity risk. Results of the study revealed that the e-comorbidity approach sensitivity ranged from $94 \%$ for atlantoaxial subluxation to $100 \%$ for cardiovascular risk. Sensitivity of ICD-10 extracted comorbidities ranged from $8 \%$ for anxiety to $100 \%$ for tumors; while sensitivity of comorbidity(ies) extraction using clinicreported outcomes ranged from $4 \%$ for falls risk to $100 \%$ for diabetes and tumors. The median positive predictive value and negative predictive value were $97.7 \%$ and $99.6 \%$ for the e-comorbidity tool versus $61.8 \%$ and $97.4 \%$ for the ICD-10 codes, respectively. The adherence of the patients to antirheumatic therapy was significantly higher in the active group who were monitored electronically, whereas stopping DMARDs for intolerability/side effects was significantly greater in the control group. Regarding monitoring and management of the comorbidity risk, number of procedure/screening tests for comorbidity risk assessment was significantly higher in the e-comorbidity group. The study concluded that patientreported e-comorbidity outperformed the routine medical recording system had a positive impact on the patients' adherence to therapy and mortality risk. Therefore, it can play a role in standard health care management and research. 
Reclassifying RA patients according to their comorbidity risk would have a positive impact on their treatment outcomes, adherence to medications with subsequent positive impact on the patients' mortality and deformity risks.

\section{Conclusion}

Telehealth can be defined as the use of information and telecommunication technology to provide patients with health care at a distance. Current research shows evidence of the effectiveness and acceptability of telemedicine in the medical and surgical fields. Making the data meaningful, particularly using ambient feedback, has also attracted people to adopt behavioral changes regardless of their health status. With the rapid expansion in digital technology, there will be plethora of user-friendly telehealth platforms that fit different people health conditions and lifestyles. More effort is expected toward users' privacy protection and use of data collected.

\section{Disclosure}

The author reports no conflicts of interest in this work.

\section{References}

1. Lewtas J. Telemedicine in rheumatology. J Rheumatol. 2001; 28(8):1745-1746.

2. El Miedany Y, El Gaafary M, Youssef S, et al. Toward electronic health recording: evaluation of electronic patient-reported outcome measures system for remote monitoring of early rheumatoid arthritis. J Rheumatol. 2016;43(12):2106-2112.

3. Text of the Telehealth Modernization Act of 2013. Available from: https://www.congress.gov/bill/114th-congress/house-bill/691/text? format $=$ txt. Accessed January 25, 2017.

4. American Telemedicine Association. What is Telemedicine? Available from: https://s3.amazonaws.com/rdcms-himss/files/production/public/ HIMSSorg/Content/files/Line\%2016\%20-\%20What\%20Is\%20Telemedicine.pdf. Accessed January 24, 2017.

5. Doarn CR, Pruitt S, Jacobs J, et al. Federal efforts to define and advance telehealth--a work in progress. Telemed J E Health. 2014;20(5):409-418.

6. Langer B, Wetter T. Physicians'attitudes towards health telematics - an empirical survey. Stud Health Technol Inform. 2000;77:1106-1111.

7. Harrison PV, Kirby B, Dickinson Y, Schofield R. Teledermatology high technology or not? J Telemed Telecare. 1998;4:31-32.

8. Stanberry B. Telemedicine: barriers and opportunities in the 21st century. J Intern Med. 1998;129:123-127.

9. GÖK H. Telemedicine in rheumatology. TurkJ Rheumatol. 2013;28(1):1.

10. Davis P, Howard R, Brockway P. An evaluation of telehealth in the provision of rheumatologic consults to a remote area. J Rheumatol. 2001;28(8):1910-1913.

11. Rosenfeld BA, Dorman T, Breslow MF, et al. Intensive care unit telemedicine: alternate paradigm for providing continuous intensivist care. Crit Care Med. 2000;28(12):3925-3931

12. Grigsby J, Sanders JH. Telemedicine: where it is and where it's going. Ann Intern Med. 1998;129(2):123-172.

13. Morrissey J. A phone call away: foreign doctors tap U.S. expertise through telemedicine links. Mod Health C. 1998;28:18-22.

14. Erickson A [webpage on the Internet]. Rheumatology Outreach Clinics; 2016. Available from: https://www.unmc.edu/news.cfm?match=19232. Accessed January 25, 2017.
15. Castle-Clarke $\mathrm{S}$, Imison $\mathrm{C}$. The digital patient: transforming primary care? Research Report 2016. www.Nuffield Trust.org.uk. file:///F:/ Telehealth/the-digital-patient-web-final.pdf. Accessed January 25, 2017.

16. Department of Health and UK Trade \& Investment The UK: Your partner for digital health solutions. Department of Health and UK Trade \& Investment; 2015. Available from: https://www.gov.uk/ government/ publications/the-uk-your-partner-for-digital-health-solutions/the-ukyourpartner-for-digital-health-solutions. Accessed 26 January 2017.

17. Holt TA, Fletcher E, Warren F, et al. Telephone triage systems in UK general practice: analysis of consultation duration during the index day in a pragmatic randomised controlled trial. Br J Gen Pract. 2016;66(644): e214-e218.

18. Aitken M and Lyle J. Patient adoption of mHealth: Use, evidence and remaining barriers to mainstream acceptance. IMS Institute for Healthcare Informatics; 2015. Available from: www.imshealth.com/files/web/ IMSH\%20Institute/Reports/Patient\%20Adoption\%20of\%20mHealth/ IIHI_Patient_Adoption_of_mHealth.pdf. Accessed January 25, 2017.

19. Misra S. NHS Health Apps Library closing amid questions about app security \& quality: what can we learn? iMedical Apps. Medpage Today. Available from: http://www.imedicalapps.com/2015/10/nhshealth-apps-library-closing-commentary/. Accessed January 25, 2017.

20. Philips collaborates with Accenture to create first proof of concept for delivering vital patient data via Google Glass 2013. Available from: https://newsroom.accenture.com/industries/communications/philips-collaborates-with-accenture-to-create-first-proof-of-concept-for-deliveringvital-patient-data-via-google-glass.htm. Accessed January 25, 2017.

21. Car J, Gurol-Urganci I, de Jongh T, Vodopivec-Jamsek V, Atun R. Mobile phone messaging reminders for attendance at healthcare appointments. Cochrane Database Syst Rev. 2012;7:CD007458.

22. Atack $L$ and Luke $R$. The impact of validated, online health education resources on patient and community members' satisfaction and health behaviour. Health Educ J. 2012;71(2):211-218.

23. Rainie $L$. The rise of the e-patient, Lee Rainie from the Pew Internet and American Life Project presentation at the Medical Library Association, Oct 7, 2009. Available from: http://www.pewinternet.org/2009/10/07/ the-rise-of-the-e-patient-2/. Accessed January 25, 2017.

24. Robertson N, Polonsky M, McQuilken L. Are my symptoms serious Dr Google? A resource-based typology of value co-destruction in online self-diagnosis. Austr Marketing J. 2014;22(3):246-256.

25. Fox S, Duggan M. Pew Research Internet Project. Available from: http://www.pewinternet.org/2013/01/15/health-online-2013/. Accessed January 26, 2017.

26. Berland GK1, Elliott MN, Morales LS et al. Health information on the Internet: accessibility, quality, and readability in English and Spanish. JAMA. 2001;285(20):2612-2621.

27. Lusignan S, Mold F, Sheikh A, et al. Patients online access to their electronic health records and linked online services: a systematic interpretative review. BMJ Open. 2014;4(9):e006021.

28. Delbanco T, Walker J, Bell SK, et al. Inviting patients to read their doctors' notes: a quasiexperimental study and a look ahead. Ann Intern Med. 2012;157(7):461-470

29. El Miedany Y, El Gaafary M, El Arousy N, Ahmed I, Youssef S, Palmer D. Arthritis education: the integration of patient-reported outcome measures and patient self-management. Clin Exp Rheumatol. 2012;30(6):899-904

30. El Miedany Y (e), El Gaafary M, Youssef S, Bahlas S, Hegazi M, Ahmed I. E-comorbidity: evaluation of the validity of electronic comorbidity assessment in identifying comorbid conditions among patients with rheumatoid and psoriatic arthritis. Arthritis Rheumatol. 2016;68(Suppl 10):1-4550.

31. El Miedany Y, El Gaafary M, Youssef S, Palmer D. Electronic patient reported outcome measures (e-PROMS) for early arthritis in standard clinical practice: a pilot study. Ann Rheum Dis. 2015;74(Suppl 2): 65.

32. Barrett MA, Humblet O, Hiatt RA, Adler NE. Big data and disease prevention: from quantified self to quantified communities. Big Data. 2013;1(3):168-175. 
33. Hänsel K, Wilde N, Haddadi H, Alomainy A. Challenges with current wearable technology in monitoring health data and providing positive behavioural support. MobiHealth. 2015;15:14-16.

34. Apple ResearchKit and CareKit. Available form: http://www.apple.com/ researchkit/. Accessed April 5, 2017.

35. Ananthanarayan S, Siek KA. Persuasive wearable technology design for health and wellness. In: Pervasive Computing Technologies for Healthcare (PervasiveHealth), 2012 6th International Conference. 236-240. San Diego, CA, USA.

36. Gockley R, Marotta M, Rogoff C, Tang A. Aviva: a health and fitness monitor for young women. In CHI'06 extended abstracts on human factors in computing systems. 2006:1819-1824. Montreal, QC, Canada.

37. Maan S, Merkus B, Ham J, Midden C. Making it not too obvious: the effect of ambient light feedback on space heating energy consumption. Energ Effic. 2011;4(2):175-183.

38. Ham J, Midden C. Ambient persuasive technology needs little cognitive effort: the differential effects of cognitive load on lighting feedback versus factual feedback. In: Persuasive Technology Springer (Pub), 2010:132-142.

39. Consolvo S, McDonald DW, Toscos T, et al. Activity Sensing in the Wild: a Field Trial of Ubift Garden. Proceedings of the SIGCHI Conference on Human Factors in Computing Systems, 2008:1797-1806. Florence, Italy.

40. Swan M. Sensor mania! the internet of things, wearable computing, objective metrics, and the quantified self 2.0. J Sens Actuator Netw. 2012;1(3):217-253.

41. Ferreira A, Correia A, Silva A, et al. Why facilitate patient access to medical records. Stud Health Technol Inform. 2007;127:77-90.

42. El Miedany Y. PROMs in inflammatory arthritis: moving from static to dynamic. Clin Rheumatol. 2013;32(6):735-742.

43. El Miedany Y. e-Rheumatology: are we ready? Clin Rheumatol. 2015; 34(5):831-837.
44. Palmer D, El Miedany Y. EROMIA in inflammatory arthritis: the next step in standard practice. Br J Nurs. 2010;19(1):42-46.

45. El Miedany, El Gaafary M, Palmer D. Assessment of the utility of visual feedback in the treatment of early rheumatoid arthritis patients: a pilot study. Rheumatol Int. 2012;32(10):3061-3068.

46. El Miedany Y, Bahlas S, El Gaafary M, Youssef S, Ahmed I. Electronic patient reported outcome measures in systemic lupus erythematosus: a potential disease modifying impact on the management of disease activity flares and damage accrual. Arthritis Rheumatol. 2015;67(Suppl 10): $1-4046$

47. El Miedany YM, El Gaafary M, Youssef S, Bahlas S, Hegazi M, Ahmed I. E-comorbidity: evaluation of the validity of electronic comorbidity assessment in identifying comorbid conditions among patients with rheumatoid and psoriatic arthritis [abstract]. Arthritis Rheumatol. 2016;68(Suppl 10). Available from: http://acrabstracts. org/abstract/e-comorbidity-evaluation-of-the-validity-of-electroniccomorbidity-assessment-in-identifying-comorbid-conditions-amongpatients-with-rheumatoid-and-psoriatic-arthritis/. Accessed April 7, 2017.

48. Fox S, Fallows D. Health Searches and Email Have Become More Commonplace, but There is Room for Improvement in Searches and Overall Internet Access. 2003. Available from: http://www.pewinternet.org/files/ old-media//Files/Reports/2003/PIP_Health_Report_July_2003.pdf.pdf. Accessed January 25, 2017.

49. El Miedany Y, El Gaafary M, Youssef S, Bahlas S, Ahmed I, Hegazi M. Rheumatoid arthritis comorbidity index: development and validation of a new specific tool for classifying prognostic comorbidity in rheumatoid arthritis patients. Ann Rheum Dis. 2016;75(Supp12):154

50. El Miedany Y, El Gaafary M, Youssef S, Bahlas S, Ahmed I, Hegazi M. Psoriatic arthritis Comorbidity Index: development and validation of a new specific tool for classifying prognostic comorbidity in psoriatic arthritis patients. Rheumatol Orthop Med. 2015;2(1).
Smart Homecare Technology and TeleHealth

\section{Publish your work in this journal}

Smart Homecare Technology and TeleHealth is an international, peer-reviewed open access online journal publishing original research, reviews, editorials and commentaries on the application of technology to support people and patients at home and in assisted living centers to optimize healthcare and management resources. Specific topics in the journal include: Development and application of

\section{Dovepress}

devices within the home and embedded in appliances; Healthcare provider communication and education tools; and drug ordering and adherence. The manuscript management system is completely online and includes a very quick and fair peer-review system, which is all easy to use. Visit http://www.dovepress.com/ testimonials.php to read real quotes from published authors. 